BEAM DYNAMICS

\title{
PARTICLE DYNAMICS IN THE INJECTOR OF ION LINEAR INDUCTION ACCELERATOR
}

\author{
V.I. Karas, ${ }^{1,2}$, E.A. Kornilov ${ }^{1}$, O.V. Manuilenko ${ }^{1}$, O.V. Fedorovskaya ${ }^{1}$ \\ ${ }^{I}$ National Science Center "Kharkov Institute of Physics and Technology”, Kharkiv, Ukraine; \\ ${ }^{2}$ V.N. Karazin Kharkiv National University, Kharkiv, Ukraine \\ E-mail:karas@kipt.kharkov.ua
}

The investigations of the particle dynamics in the injector of a linear induction accelerator (LIA) in the presence of an accelerating electric field and a uniform longitudinal magnetic field of various magnitudes have been presented. It is shown that at found parameters of the system and particles the ion beam at the exit of the injector keeps the transverse dimensions and its current close to the initial, that allows to count on the accomplishment of its further transportation through the LIA section.

PACS: 41.75.-i, 52.40.Mj, 52.58.Hm, 52.59.-f, 52.65.Rr

\section{INTRODUCTION}

It is known that in LIA it is possible to produce high-energy beams for the heavy ion fusion (HIF), surface modification of various materials, radiation materials science, and other important technological applications. This accelerator is one of the most promising drivers, which not only allows to obtain high-current beams of heavy ions, but is also more competitive from an economic point of view than some other types of drivers. Therefore, the interest of scientists in the world to the problem of creating a compact, relatively safe and cheap LIA is so high (see, for example, [1 - 4]). In Ukraine, which is not an exception too, the accelerators of this type are also being investigated, for example, LIA with a collective focusing of a tubular high-current beam (HCIB), suggested at the National Science Center "Kharkov Institute of Physics and Technology" of the National Academy of Sciences of Ukraine [5, 6]. This focusing method allows to create a compact accelerator of HCIB for the above-mentioned applications.

Earlier, a number of studies has been carried out on the charge and current compensation of HCIB in the axisymmetric accelerating gap [7 - 9]. In [10], the dynamics of an ion beam transportation in an external magnetic field in the drift gap of the LIA with collective focusing has been numerically studied. The variants of the HCIB charge compensation in this system have been considered. It has been found that the start time and duration of additional electrons' injection, as well as their speed, are of great importance for the ion beam uniform compensation. It is shown that in the most acceptable variant of the HCIB compensation, the ion beam current at the exit from the drift gap is close to the initial one, and since the electron beam also retains its current, the HCIB current is almost compensated at the system exit.

The compensation variant found in [12] allows us to keep the HCIB quality, required for HIF, but further improvement of the compensation method is necessary to reduce the energy spread and angular divergence of the ion beam.

In [13], the transportation and acceleration of the HCIB in the LIA magnetically insulated gap have been studied. The parameters of the beams and the system, at which the transportation and acceleration of the compensated ion beam (CIB) are realized in a magnetically insulated gap with maintaining its current, density, cross section close to the original have been found. It is shown that the HCIB accelerates almost uniformly, maintaining the energy homogeneity and the crosssection at the exit from the magnetically insulated gap.

The transportation and acceleration of the ion beam in a system consisting of a magnetically insulated and two drift gaps have been studied [14]. It is shown that the HCIB parameters at the exit from the LIA section in the presence of: a magnetic field, injection of the accompanying electron beam, and programmed injection of an additional electron beam remain acceptable for a number of important technological applications.

In [15], it was shown that at the suggested parameters of the beams and the system, it was managed to transport the CIB with a current of 1MA in the LIA section, having retained its energy and current at the exit of the section similar to the initial ones.

An important and difficult task, in addition to the HCIB compensation in the LIA, is to obtain a highdensity ion beam in the accelerator injector. There are many different works, dedicated to investigations an ion beam formation in diodes or similar structures (see, for example, [16-22]). Basically, milliampere or ampere ion beams can be obtained in such systems. Many of the facilities currently available make it possible to obtain ion beams for various purposes, including HIF, but for other types of drivers [17 - 20]. In LIA with collective focusing, we expect to obtain sufficiently high currents (kA), therefore, an appropriate ion source is also needed. In [20 - 22], ion beams have been experimentally obtained and their currents were measured.

With a fairly compact and relatively simple design, the authors succeeded in obtaining current densities on the order of $50 \ldots 250 \mathrm{~A} / \mathrm{cm}^{2}$. The results of experiments on the production of nitrogen ion beams with a current density of $54 \mathrm{~A} / \mathrm{cm}^{2}$ and with a beam purity of $94 \%$ in a magnetically insulated ion diode are presented in [21]. To generate ions, a gas puff plasma gun was used. In turn, beams of metal ions with a current density of $160 \ldots 230 \mathrm{~A} / \mathrm{cm}^{2}$ have been obtained in a magnetically insulated ion diode, where a vacuum arc plasma gun, the most suitable device for this purpose, was used as an ion source [22]. In [21, 22], the ion beam current density was measured using a biased ion collector. As a pulsed power source, in particular, to generate an accelerating electric field, a Marx generator was used. 
In this paper, the particle dynamics in the LIA injector, based on an experimental model of an existing ion source, elaborated and tested at Toyama University (Japan) $[21,22]$, is investigated. The optimization of the system and the particles parameters has been carried out, which provides a sufficiently high quality of the HCIB at the exit of the injector and allows realizing its transport through the LIA section in prospect.

\section{THE HCIB TRANSPORTATION IN THE INJECTOR}

This section presents the results of a numerical study of the particles dynamics in the injector, carried out using the 3D code KARAT [23], which is capable to solve problems of this class. KARAT is a fully electromagnetic code based on particle-in-cell method. It is intended for solving non-stationary electrodynamic problems, having complex geometry and including dynamics, in the general case, of relativistic particles (electrons, ions, neutrals).

Numerical simulations have been carried out in xyzgeometry. The numerical parameters were set in such a way that the conditions ensuring the numerical stability of the calculations [24] were met.

Fig. 1 shows the geometry of the problem, where $x_{D}$ is the transversal dimension, and $z_{D}$ is the longitudinal size of the system, $R_{\min }=0.007 \mathrm{~m}$ and $R_{\max }=0.014 \mathrm{~m}$ are the inner and outer radii of tubular ion and electron beams. The electron beam is needed to compensate the HCIB charge. The beams injected to the left are shown in blue.

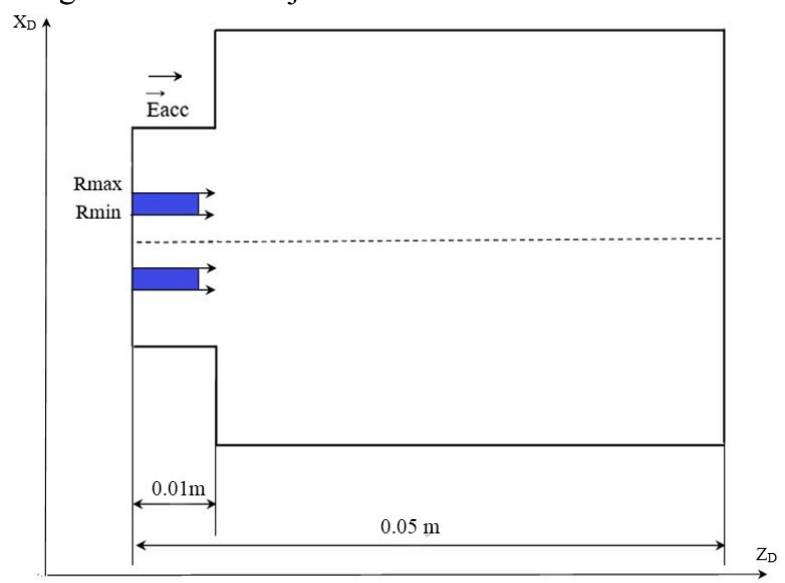

Fig. 1. Section of the system by the plane $x \mathrm{Oz}$ along $z$. Beams injection areas

The injector has the shape of a cylinder of different section - with a radius of $0.03 \mathrm{~m}$ and a length of $0.01 \mathrm{~m}$ at the very beginning of the system, and then a radius of $0.07 \mathrm{~m}$ and a length of $0.04 \mathrm{~m}$. The total length of the injector is $0.05 \mathrm{~m}$.

In Fig. 1 there is an axially symmetric geometry of the beams (at the initial moment of time) and the system along the $z$ axis, the axis of symmetry is indicated dotted line.

We have considered four variants of the HCIB transportation in the LIA injector, where an external longitudinal uniform magnetic field $B_{0}$ exists throughout the simulation area: 1) at the initial moment of time, ion (protons) and electron beams with density $n_{b i}=n_{b e}=4 \cdot 10^{18} \mathrm{~m}^{-3}$, energy $W_{k \mathrm{i}}=W_{k e}=30 \mathrm{keV}, B_{0}=2 \mathrm{~T}$; 2) $n_{b i}=n_{b e}=4 \cdot 10^{18} \mathrm{~m}^{-3}, W_{k i}=W_{k e}=30 \mathrm{keV}, B_{0}=1 \mathrm{~T}$;
3) $n_{b i}=n_{b e}=1 \cdot 10^{18} \mathrm{~m}^{-3}, W_{k i}=W_{k e}=30 \mathrm{keV}, B_{0}=0.5 \mathrm{~T}$ are injected from left; in all three cases, on the length (from the very beginning of the system to $0.01 \mathrm{~m}$ ) accelerating electric field $E_{0}=3 \mathrm{MV} / \mathrm{m}$ is applied; 4) $n_{b i}=$ $n_{b e}=4 \cdot 10^{18} \mathrm{~m}^{-3}$, energy $W_{k i}=W_{k e}=30 \mathrm{keV}, B_{0}=2 \mathrm{~T}, E_{0}=0$.
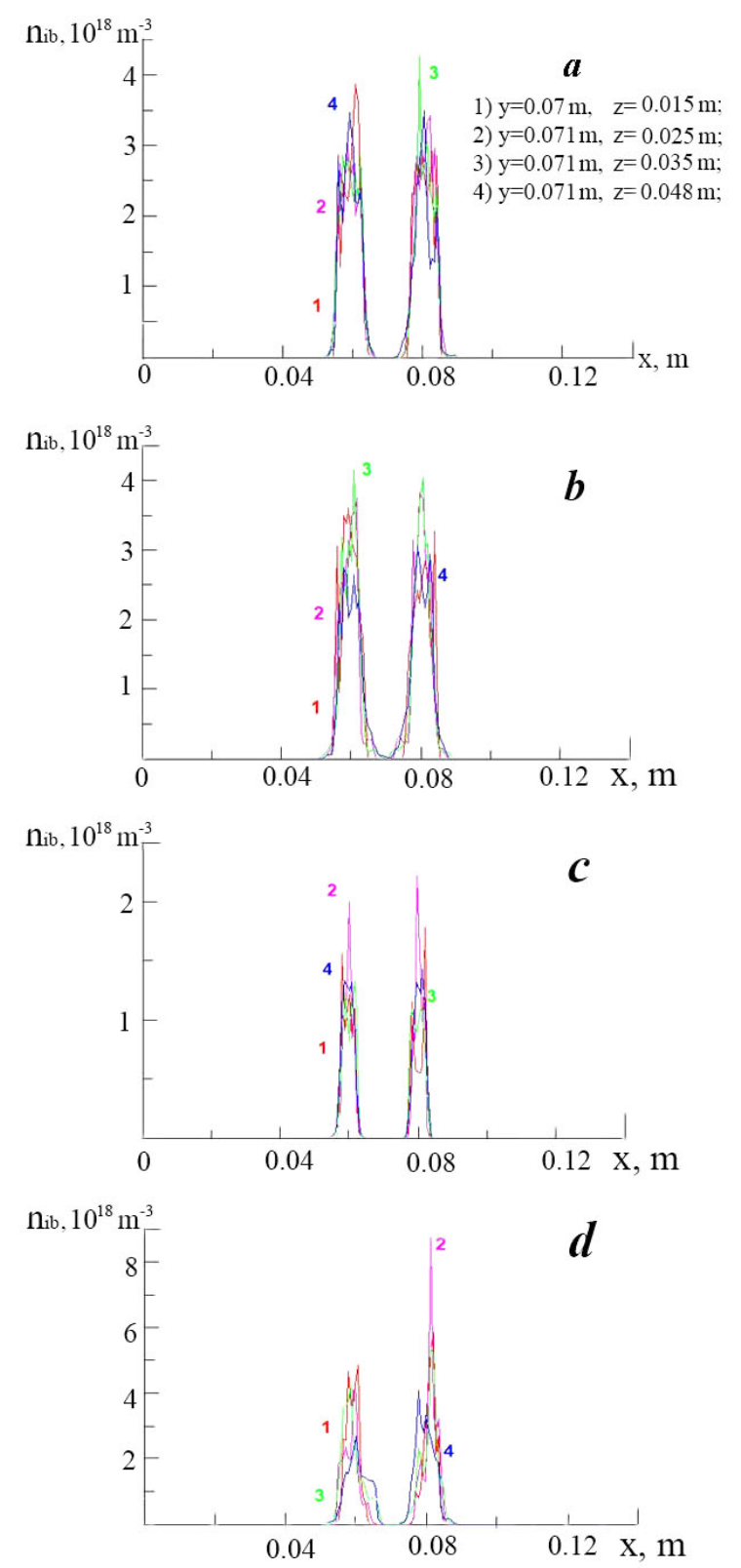

Fig. 2. The ion beam density vs the transverse coordinate $x$ at various points on the beam section and along $z$ : the first option (a); the second option (b); the third option (c); the fourth option (d)

In this paper, we do not consider the producing of a plasma by means a plasma gun, because this method is well described and implemented in experiments [21, 22]. We investigate the transport of particles from the anode, which has corresponding hole, through which the plasma passes with a given energy, density, thus ion and electron beams, having been transported to the exit of the injector, are formed. When the particles pass through the system, the electrons are not removed from the injector (as it has been done in the experiments), but accompanies the HCIB along the system. This provides the ion beam charge compensation, preventing the growth of its transverse dimensions and its quality decreasing. 
In Fig. 2 it is shown the dependence of the HCIB density on the transverse coordinate $x$. It can be seen that in the first two cases the density is about $20 \%$ lower than the initial one, but the CIB slightly diverges in the transverse direction (see Fig. 2,a,b). In the second case (see Fig. 2,b), when the external magnetic field is lower, the HCIB broadens more, since the electrons, confining the CIB, are practically not magnetized and also have a greater divergence. At the beginning of the system, the electron beam is decelerated by its own space charge field and accelerating field, that leads to its density increasing in the beginning of the system. As a result, the oscillations of the longitudinal velocity component some electrons stop, some pass further, some go back have appeared. Thus, the electron beam density becomes inhomogeneous and, since the ion beam interacts with the electron one, passing simultaneously with it through the system, then the CIB density changes, both over the cross section and along the system.
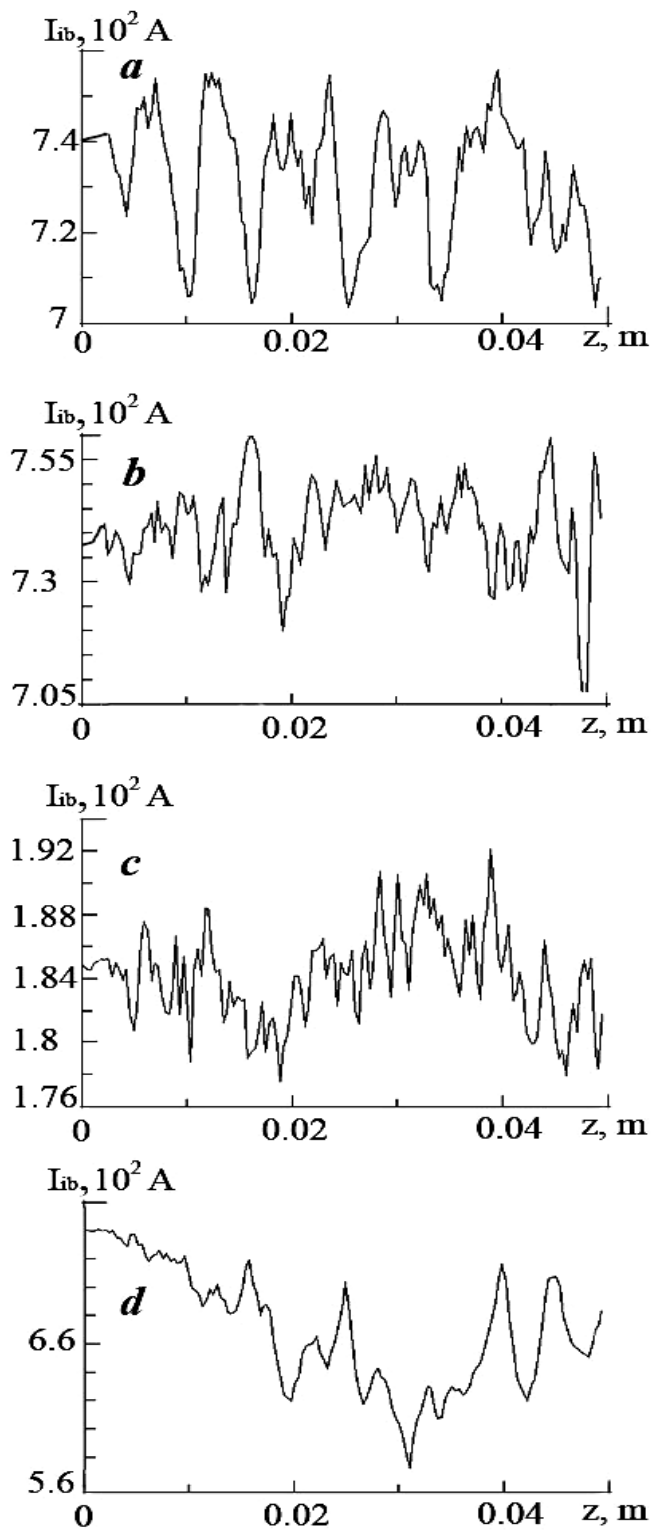

Fig. 3. The longitudinal component of the ion beam current $v$ s the longitudinal coordinate $z$ : the first option (a); the second option (b); the third option (c); the fourth option (d)
That all is also right for the third variant, but the system parameters in this case have been chosen in such a way to minimize both the divergence of the beams and the magnetic field effect on the ions, since its value is greater as in the first, as in the second cases, although ions are not magnetized (see Fig. 2,c). In the fourth case, when the accelerating field is absent, the density distribution over the CIB cross-section is less homogeneous (see Fig. 2,d): the ion beam is noticeably compressed in the center of the injector and broadened at the end of the system.
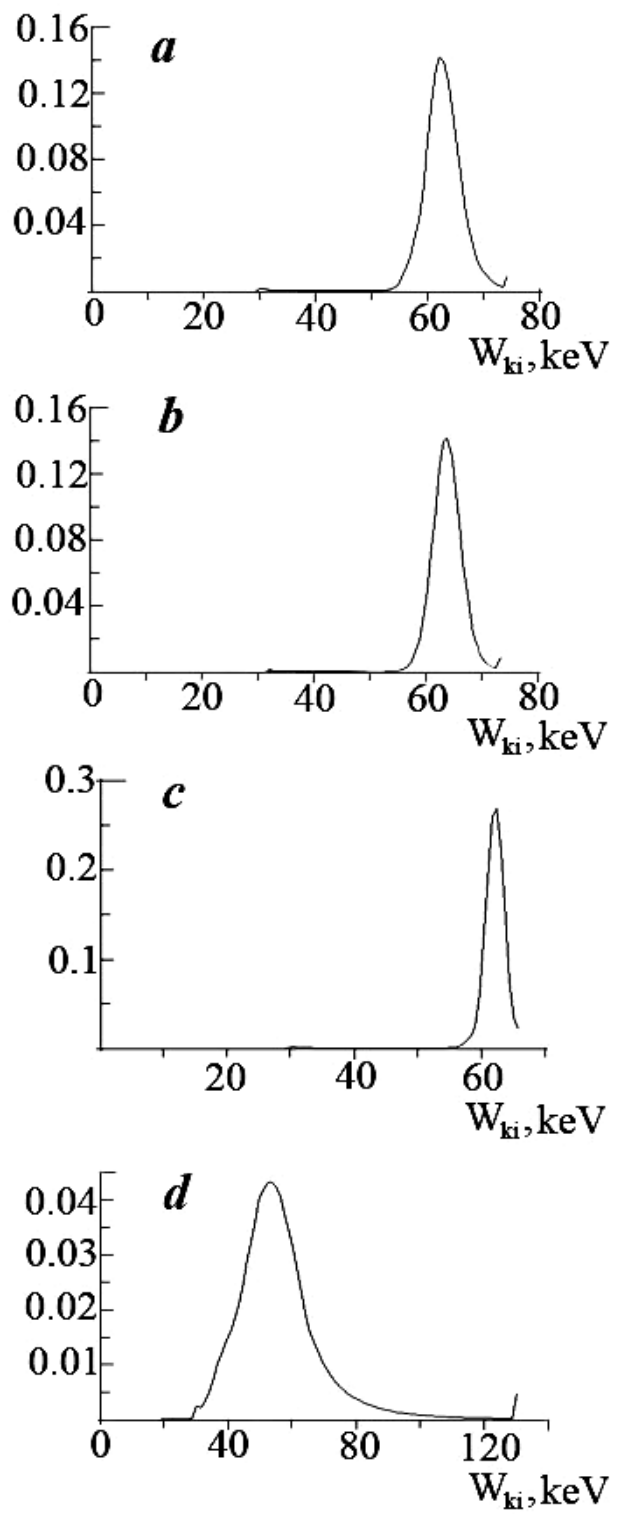

Fig. 4. The ion distribution function vs energy: the first option (a); the second option (b); the third option (c); the fourth option (d)

Fluctuations of the electron beam velocity have led not only to the inhomogeneity of its density, but also to current oscillations and, as a result, to the HCIB current fluctuations (see Fig. 3). In the first (see Fig. 3,a) and in the second (see Fig. 3,b) cases, the amplitude of the CIB current fluctuations does not exceed 5\%. Despite the decrease of the CIB density, its current has remained on average unchanged, since the ion velocity increased about 1.3 times, and the HCIB density decreased by a similar amount. In the third variant (see Fig. 3,c), the oscillations amplitude does not exceed $4 \%$. It can be seen that in this 
case the CIB has been focused; its density increased about 1.3 times, and the cross section decreased 1.75 times. Since the CIB speed increases 1.3 times, the current remains unchanged. In the fourth case, the HCIB pulls the electron beam through the system, using only its own energy, which increased at the beginning of the system due to the electron beam locking. In this case, the CIB has noticeable current deviations from the initial value (up to $23 \%$ ), and at the exit from the injector the HCIB current is lower than the initial value by $7 \%$.

As a result of large negative space charge arising the HCIB acquires energy equaled almost to the electron beam energy. In turn, in the external electric field only the "head" of the HCIB is accelerated, so that after a one ion flight time, the ion beam has energy gained only by means the field of negative space charge. The energy, acquired in the accelerating field is spent on pulling the electron beam through without significant loss of its quality.

Despite the inhomogeneous HCIB compensation and the necessity to pull the electron beam through the injector, the ion beam remains monoenergetic in the first three options with an energy of $62 \mathrm{keV}$ at the exit from the system (Fig. 4,a,b,c). In the third variant, the CIB practically has no energy spread (see Fig. 4,c). In the fourth case, the HCIB has a significant energy spread with ions accelerated up to $130 \mathrm{keV}$, while the average CIB energy is $53 \mathrm{keV}$ (Fig. 4,d).

\section{CONCLUSIONS}

In this work, the dynamics of the ion beam in the LIA injector for four variants has been studied: 1) and 2) have different values of the external magnetic field: $B_{0}=2 \mathrm{~T}$ and $B_{0}=1 \mathrm{~T}$, respectively, and the same HCIB density, accelerating electric field $E_{0}=3 \mathrm{MV} / \mathrm{m} ; 3$ ) the density of the ion beam is 4 times lower than in previous options, $B_{0}=0.5 \mathrm{~T}, E_{0}=3 \mathrm{MV} / \mathrm{m}$; 4) the parameters of the beams and the system, as in 1), except for $E_{0}=0$. The system parameters have been chosen in a special way to provide the CIB quality at the exit of the injector as high as possible. It has been found that the HCIB acceleration occurred primarily due not to the applied electric field, but to the space charge field of the electron beam having been arisen because of its deceleration. As a result, the electron beam density becomes inhomogeneous. The HCIB pulls the electron beam through the system by its space charge field, so that small fluctuations in the density and current of the ion beam arise (the deviation from the initial value does not exceed $5 \%$ ). In this case, the electron beam compensates the HCIB in the entire region, which allows keeping a sufficiently high quality of the ion beam. It has been shown that in 1) - 3) cases, when there the accelerating electric field is applied, there is practically no the ion beam divergence. In this case, the accelerated CIB with an energy of $62 \mathrm{keV}$ remains monoenergetic.

It is shown that in the absence of the electric field (4th case), the HCIB energy at the exit from the injector is $10 \mathrm{keV}$ less than in the other three variants, since there is no addition source of the energy, which can be expended in transporting the electron beam. This leads to a significant energy spread and a decrease in the ion beam quality.
The capability of transportation of the HCIB with optimal parameters has been demonstrated in the injector based on a diode developed and tested in Japan [21]. It is shown that the CIB current remains close to the initial one at the system output in the first three cases. In the third variant, the ion beam at the exit from the injector remains almost unchanged (with the exception of increased energy) and is more perspective for further study, for example, the HCIB transportation through the LIA section.

In the case of retaining the ion beam quality at the exit of the LIA section, it would be used for a number of important technological applications, including HIF. Further research will be devoted to this issue.

\section{REFERENCES}

1. A. Friedman, J.J. Barnard, R.H. Cohen, D.P. Grote, S.M. Lund, W.M. Sharp, A. Faltens, E. Henestroza, J.Y. Jung, J.W. Kwan, E.P. Lee, M.A. Leitner, B.G. Logan, J.L. Vay, W.L. Waldron, R.C. Davidson, M. Dorf, E.P. Gilson, and I.D. Kaganovich. Beam dynamics of the Neutralized Drift Compression Experiment-II, a novel pulse-compressing ion accelerator // Physics of Plasma. 2010, v. 17(5), № 056704, p. 1-9.

2. R.O. Bangerter, A. Faltens, P.A. Seidl. Accelerators for Inertial Fusion Energy Production // Reviews of Accelerator Science and Technology. 2013, v. 6, p. 85-116.

3. C. Ekdahl, Fellow, IEEE, C.A. Carlson, D.K. Frayer, B.T. McCuistian, C.B. Mostrom, M.E. Schulze, C.H. Thoma. Emittance Growth in the DARTH-II Linear Induction accelerator // IEEE Transaction of Plasma Science. 2017, v. 45, № 11, p. 2962-2973.

4. P.A. Seidl, A. Persaud, W.L. Waldron, J.J. Barnard, R.C. Davidson, A. Friedman, E.P. Gilson, W.G. Greenway, D.P. Grote, I.D. Kaganovich, S.M. Lidia, M. Stettler, J.H. Takakuwa, T. Schenkel. Short intense ion pulses for materials and warm dense matter research // Nuclear Instruments and Methods in Physics Research A. 2015, v. 800, p. 98-103.

5. V.I. Karas', V.V. Mukhin, A.M. Naboka. About compensated ion acceleration in magnetoisolated systems // Sov. J. Plasma Phys. 1987, v. 13, № 4, p. 281-283.

6. V. Batishchev, V.I. Golota, V.I. Karas', et al. Linear induction accelerator of charge-compensated ion beams for ICF // Plasma Phys. Rep. 1993, v. 19, № 5, p. 611-646.

7. N.G. Belova, V.I. Karas', Yu.S. Sigov. Numerical simulation of charged particle beam dynamics in axial symmetric magnetic field // Sov. J. Plasma Phys. 1990, v. 16, № 2, p. 115-121.

8. N.G. Belova, V.I. Karas'. Optimization of HighCurrent Ion Beam Acceleration and Charge Compensation in Two-Cusps of Induction Linac // Plasma Physics Reports. 1995, v. 21, № 12, p. $1005-$ 1013.

9. V.I. Karas', N.G. Belova. Acceleration and stability of high-current ion beams in two accelerating gaps of a linear induction accelerator // Plasma Phys. Rep. 1997, v. 23, № 4, p. 328-331. 
10. V.I. Karas', O.V. Manuilenko, E.A. Kornilov, V.P. Tarakanov, O.V. Fedorovskaya. Dynamics of high-current ion beam in the drift gap of induction accelerator at different variants of charge compensation // Problems of Atomic Science and Technology. Series “Plasma Physics”. 2014, № 6, p. 104-107.

11. V.I. Karas', O.V. Manuilenko, V.P. Tarakanov, and O.V. Federovskaya. Transport of the high-current ion and electron beams in accelerator drift gap in the presence of additional electron background // Plasma Phys. Rep. 2015, v. 41, p. 1108-1126.

12. V.I. Karas', O.V. Manuilenko, E.A. Kornilov, V.P. Tarakanov, O.V. Fedorovskaya. Transport and acceleration of the high-current ion beam in magneto-isolated gap // Problems of Atomic Science and Technology. Series "Plasma Electronics and New Methods of Acceleration”. 2015, № 4, p. 129-134.

13. V.I. Karas', O.V. Manuilenko, E.A. Kornilov, V.P. Tarakanov, O.V. Fedorovskaya. Numerical modeling of high-current ion beam transport with additional injection of electron beams in drift and accelerating gaps of LIA // Problems of Atomic Science and Technology. Series "Plasma Physics". 2015, № 6, p. 165-168.

14. V.I. Karas', O.V. Manuilenko, E.A. Kornilov, V.P. Tarakanov, O.V. Fedorovskaya. Dynamics of the high-current ion beam in a section of the linear induction accelerator // Problems of Atomic Science and Technology. Series "Nuclear and Physics investigations”. 2016, № 6, p. 52-55.

15. V.I. Karas', O.V. Manuilenko, E.A. Kornilov, V.P. Tarakanov, O.V. Fedorovskaya. High-current ion beam compensation in a section of an induction LINAC // Problems of Atomic Science and Technology. Series "Plasma Electronics and New Methods of Acceleration”. 2018, № 4, p. 91-96.

16. Chirko, Ya.E. Krasik, and J. Felsteiner. Ion beam generation in a diode with a ferroelectric anode //
Journal of Applied Physics. 2002, v. 91, № 12, p. 9487-9493.

17. J.W. Kwan, L. Ahle, D.N. Beck, et al. Ion sources and injectors for HIF induction linacs // Nuclear Instruments and Methods in Physics Research. 2001, v. A464, p. 379-387.

18. I. Brown. Vacuum Arc Ion Sources anode // Journal of Applied Physics. 2002, v. 91, № 12.

19. D.P. Grote, J.W. Kwan, G.A. Westenskow. Design and modeling of the multibeam injector anode // Nuclear Instruments and Methods in Physics Research. 2007, v. A577, p. 58-64.

20. K. Masugata, R. Tejima, M. Higashiyama, et al. Generation of an intense pulsed heavy-ion beam by a By-type, magnetically insulated ion diode with an active ion source // Plasma Devices and Operations. 2005, v. 13, № 1, p. 57-65.

21. H. Ito, H. Miyake, and K. Masugata. Diagnosis of high-intensity pulsed heavy ion beam generated by a novel magnetically insulated diode with gas puff plasma gun // Review of Scientific Instruments. 2008, v. 79, p. 103502-1-103502-4.

22. Hiroaki Ito, Yasushi Ochiai and Katsumi Masugata. Development of High-current Pulsed Heavy-ionbeam Technology for Applications to Materials Processing // Journal of the Korean Physical Society. 2011, v. 59, № 6, p. 3652-3656.

23. V.P. Tarakanov. User's Manual for Code KARAT // Spri-ngfield VA: Berkley Research Associates Inc. 1992, p. 137.

24. O.V. Manuilenko, K.M. Minaeva. Ion energy and angular distributions in rf capacitively coupled plasma sources // Problems of Atomic Science and Technology. Series "Plasma Electronics and New Methods of Acceleration”. 2006, № 5, p. 116-121.

Article received 30.09.2019

\section{ДИНАМИКА ЧАСТИЦ В ИНЖЕКТОРЕ ИОННОГО ЛИНЕЙНОГО ИНДУКЦИОННОГО УСКОРИТЕЛЯ}

\section{В.И. Карась, Е.А. Корнилов, О.В. Мануйленко, О.В. Федоровская}

Проведены исследования динамики частиц в инжекторе линейного индукционного ускорителя (ЛИУ) при наличии ускоряющего электрического и однородного продольного магнитного полей различных величин. Показано, что при найденных параметрах системы и частиц ионный пучок на выходе из инжектора сохраняет поперечные размеры и ток, близкими к первоначальным, что позволяет рассчитывать на реализацию его дальнейшей транспортировки через секцию ЛИУ.

\section{ДИНАМІКА ЧАСТИНОК В ІНЖЕКТОРІ ІОННОГО ЛІНІЙНОГО ІНДУКЦІЙНОГО ПРИСКОРЮВАЧА В.І. Карась, С.А. Корнілов, О.В. Мануйленко, О.В. Федоровська}

Проведено дослідження динаміки частинок в інжекторі лінійного індукційного прискорювача (ЛІП) при наявності прискорюючого електричного і однорідного поздовжнього магнітного полів різних величин. Показано, що при знайдених параметрах системи і частинок іонний пучок на виході з інжектора зберігає поперечні розміри та струм, близькими до первинних, що дозволяє розраховувати на реалізацію його подальшого транспортування через секцію ЛІП. 